\title{
Low temperature of radiofrequency ablation at the target sites can facilitate rapid progression of residual hepatic VX2 carcinoma
}

\author{
Shan $\mathrm{Ke}^{\dagger}$, Xue-mei Ding ${ }^{\dagger}$, Jian Kong, Jun Gao, Shao-hong Wang, Yan Cheng, Wen-bing Sun ${ }^{*}$
}

\begin{abstract}
Background: Rapid progression of residual tumor after radiofrequency ablation (RFA) of hepatocellular carcinoma has been observed increasingly. However, its underlying mechanisms remain to be clarified. The present study was designed to determine whether low temperature of RFA at the target sites facilitates rapid progression of residual hepatic VX2 carcinoma and to clarify the possible underlying mechanisms.
\end{abstract}

Methods: The residual VX2 hepatoma model in rabbits was established by using RFA at 55,70 and $85^{\circ} \mathrm{C}$. Rabbits that were implanted with VX2 hepatoma but did not receive RFA acted as a control group. The relationship between rapid progression of residual hepatic VX2 carcinoma and low temperature of RFA at the target sites was carefully evaluated. A number of potential contributing molecular factors, such as proliferating cell nuclear antigen (PCNA), matrix metalloproteinase 9 (MMP-9), vascular endothelial growth factor (VEGF), hepatocyte growth factor (HGF) and Interleukin-6 (IL-6) were measured.

Results: The focal tumor volume and lung metastases of RFA-treated rabbits increased significantly compared with the control group $(P<0.05)$, and the greatest changes were seen in the $55^{\circ} \mathrm{C}$ group $(P<0.05)$. Expression of PCNA, MMP-9, VEGF, HGF and IL-6 in tumor tissues increased significantly in the RFA-treated groups compared with the control group, and of the increases were greatest in the $55^{\circ} \mathrm{C}$ group $(P<0.05)$. These results were consistent with gross pathological observation. Tumor re-inoculation experiments confirmed that low temperature of RFA at the target sites facilitated rapid progression of residual hepatic VX2 carcinoma.

Conclusions: Insufficient RFA that is caused by low temperature at the target sites could be an important cause of rapid progression of residual hepatic VX2 carcinoma. Residual hepatic VX2 carcinoma could facilitate its rapid progression through inducing overexpression of several molecular factors, such as PCNA, MMP-9, VEGF, HGF and IL-6.

\section{Background}

Hepatocellular carcinoma (HCC) is still one of the most important diseases for health care systems due to its high morbidity, mortality and increasing incidence worldwide [1]. Although hepatic resection and transplantation have been considered as the main curative therapies for HCC, the vast majority of patients are not eligible when this tumor is detected. Only about $20 \%$ of HCC cases are resectable [2,3]. Currently, various local ablative therapies, such as radiofrequency ablation (RFA), have been accepted as an alternative treatment

\footnotetext{
* Correspondence: wb.sun@yahoo.com.cn

+ Contributed equally

Department of Hepatobiliary Surgery, West Campus, Beijing Chao-yang Hospital Affiliated to Capital Medical University, Beijing 100043, China
}

option for HCC, because of its several advantages, such as definitive therapeutic effect, minimal invasiveness, repeatability, safety, and shorter hospitalization [3].

At present, residual tumor is one of the main obstacles that greatly hinders the effectiveness of RFA for HCC [4]. The residual tumor cannot be entirely avoided for several reasons, such as the mechanisms of RFA, the pathological characteristics of HCC, and the anatomical traits of the liver. The reasons for residual tumor can be categorized as follows: First, the target temperature for ablation cannot be easily reached due to the "heat sink" effect of blood vessels, especially large vessels, within or around the tumor [5]. Second, the operator might deliberately reduce the local intensity of RFA to avoid unintended injury when the tumor is adjacent to an 
organ such as the stomach, intestine or gallbladder. Third, the performance of overlapping ablation in a mathematically irregular fashion is difficult, especially by the percutaneous route. As a result, nests of viable tumor cells remain in the clefts between the incompletely fused coagulation zones. Finally, the microvascular invasion area that surrounds the main tumor in HCC is sometimes wider than expected, or undetected microscopic satellite tumor lesions might be present [6].

Since 2001, rapid progression of residual tumor after RFA of HCC has been observed increasingly [7,8]. Cumulative evidence has demonstrated that residual tumor after RFA might exhibit an aggressive phenotype and unfavorable prognosis [9], and even change to sarcoma [10], which leads to deterioration of the patient's condition. The conventional concepts of residual tumor have been greatly altered recently. It is believed that clarifying the underlying mechanisms of rapid progression of residual tumor might have a significant effect on the therapeutic principle and strategy of RFA for HCC [8].

Based on analysis of the aforementioned risk factors, we hypothesized that low temperature of RFA at the target sites, which leads to incomplete ablation, might play an important role in facilitating rapid progression of residual tumor of $\mathrm{HCC}$ after RFA. The present study was designed to test this hypothesis and to clarify the possible underlying mechanisms.

\section{Methods}

\section{Animals and tumor inoculation}

The experiments were performed with New Zealand white rabbits that weighed $2.5-3.0 \mathrm{~kg}$. The experiments were approved by the Animal Care Committee of Capital Medical University, Beijing, China and were performed in accordance with the institutional guidelines. The animals were anesthetized with an intravenous injection of
$35 \mathrm{mg} / \mathrm{kg}$ pentobarbital. The animals were allowed food and water ad libitum between the various procedures. A schematic diagram has been produced and added to illustrate the experimental procedures (Fig. 1). VX2 carcinoma was used to establish the model of HCC. VX2 carcinoma is an anaplastic squamous cell carcinoma that is derived from a virus-induced papilloma in wild rabbits, but appears as a carcinoma in the domestic species. VX2 tumors were first grown for 2 weeks on the hind legs of carrier rabbits and then were harvested after they reached a size of $1.5 \mathrm{~cm}$. The harvested tumors were placed into saline solution and cut into cubes of $1 \mathrm{~mm}^{3}$. Only portions of tumor tissue that did not show any macroscopic signs of necrosis were used. Abdomens of the recipient rabbits were shaved and prepared with povidone iodine, and a midline subxyphoid incision was made. The anterior surface of the liver was exposed and one of the prepared cubes of tumor tissue was implanted in the left lobe of the liver using a 21-gauge angioneedle (Becton Dickinson, Sandy, UT, USA). This method allowed the growth of a solitary, well-demarcated tumor. There was only one inoculation site in each liver. Proper aseptic technique was rigorously observed during each inoculation. After surgery, the animals were returned to their cages, kept warm, and monitored in the animal laboratory until they recovered from anesthesia. An HDI 5000 ultrasound system (Philips Healthcare, Bothell, WA, USA) with a 7.5-MHz linear probe was used to monitor the tumor size. Based on the methods described previously[11,12] and our experimental design, VX2 carcinoma nodules $>2.0 \mathrm{~cm}$ in diameter were considered appropriate for RFA. The period for tumors to reach the size of $2.0 \mathrm{~cm}$ ranged from 16 to 18 days. All inoculations were performed by the same individual investigator, who inoculated specimens of the same tumor into all rabbits to minimize inter-animal variations in tumor growth rate.

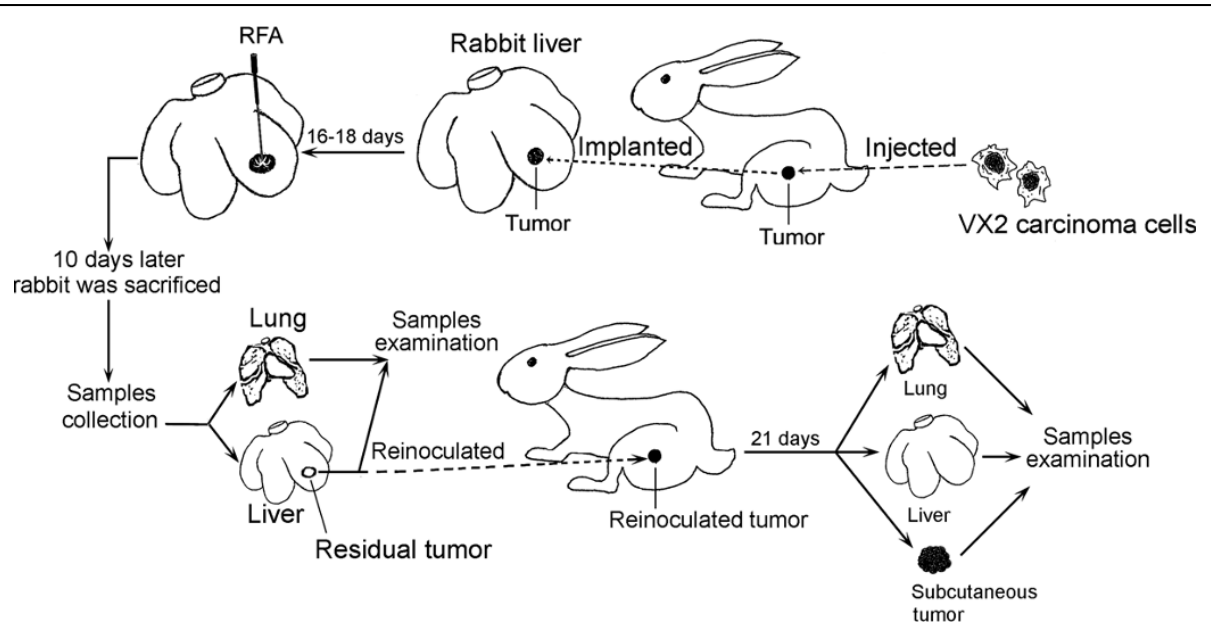

Figure 1 Schematic diagram of the whole experimental plan. 
Model of residual hepatic VX2 carcinoma following RFA The RFA procedure for residual hepatic VX2 carcinoma was standardized in advance as depicted in Fig. 1 and Fig. 2. Sixty rabbits were randomly divided into four groups of 15: group I was treated with RFA at $55^{\circ} \mathrm{C}$; group II was treated with RFA at $70^{\circ} \mathrm{C}$; group III was treated with RFA at $85^{\circ} \mathrm{C}$; and the control group received laparotomy, RFA probe puncture but no ablation. RFA was performed using the same anesthesia protocol as for carcinoma implantation. Two grounding pads were applied to the animal's flank before RFA. Abdomens of the experimental rabbits were shaved and prepared with povidone iodine, and a midline subxyphoid incision was made. The tumor size was measured and the tumor was ablated. The tumor center was also designated as the RFA center. The measured minor axis of the tumor was used to guide the release of the RFA needle electrode. Thus, residual tumor was left on both sides of the measured major axis of the tumor (shadowed area depicted in Fig. 2). An RF current generator (Model 1500X Generator; RITA Medical Systems, Manchester, GA, USA) was used to generate RF energy. To deliver RF energy, we used a 14-gauge expandable RF needle electrode (StarBurst ${ }^{\mathrm{Tm}}$ XL; RITA Medical Systems), $10 \mathrm{~cm}$ in length. Each ablation cycle lasted for $5 \mathrm{~min}$.

\section{Gross pathological analysis}

The rabbits were sacrificed by injecting an overdose of ketamine and xylazine 10 days after RFA. The liver and lungs were carefully dissected and excised. The number

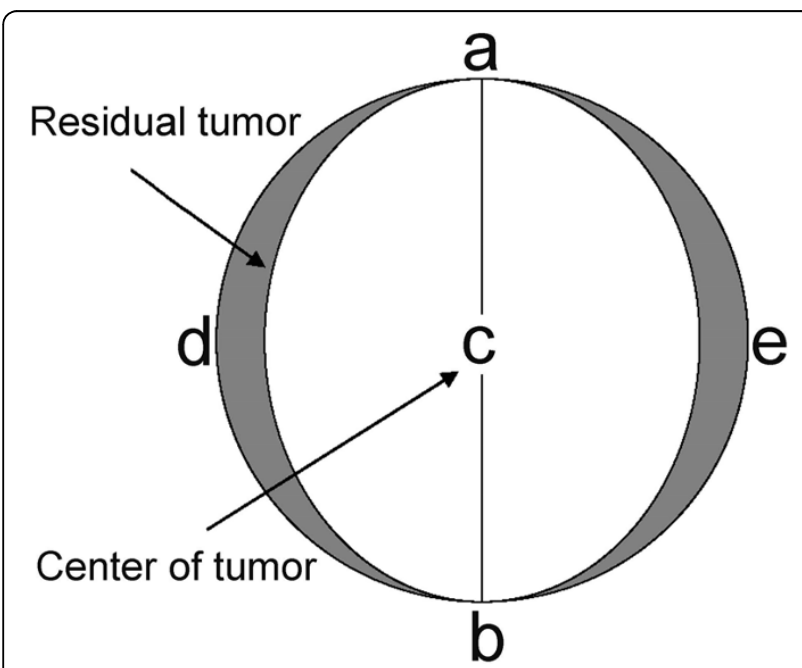

Figure 2 Sketch of residual hepatic VX2 carcinoma following RFA. The oval-shaped area of "adbe" represents the whole tumor. The line "ab" is the minor axis of the tumor and the line "de" is the major axis. The tumor center was also designated as the RFA center. The measured minor axis of the tumor was used to guide the release of the RFA needle electrode. Thus, residual tumor was left on both sides of the measured major tumor axis (shadowed area). and size of masses were noted. The pathological findings could thus be compared directly with the tumor numbers, volumes and locations. Quantitative evaluation of the lung metastatic nodules was made by two observers using the following procedures: macroscopic study by stereoscopic magnifying glass (Olympus SZH, Zeiss Stemi DV4, Germany) and counting the metastatic nodules on the pleural surface of the whole lobules [13]. The variation between the observers' findings was $<5 \%$.

\section{Immunohistochemical analysis}

The streptavidin-peroxidase two-step method was used for immunohistochemical detection of matrix metalloproteinase 9 (MMP-9), vascular endothelial growth factor (VEGF) and proliferating cell nuclear antigen (PCNA). Representative $5-\mu \mathrm{m}$ tissue sections were cut from paraffin-embedded specimens. The sections were washed three times for 3 min with PBS, and blocked with a solution of $30 \mathrm{~mL} / \mathrm{L}$ hydrogen peroxide in ethanol for $10 \mathrm{~min}$ at room temperature. They were immersed in $30 \mathrm{~mL} / \mathrm{L}$ normal horse serum for $10 \mathrm{~min}$ at room temperature. The sections were incubated for $1 \mathrm{~h}$ with primary antibodies (mouse monoclonal antibodies; Abcam, Cambridge, UK) specific to MMP-9 (dilution 1:50), VEGF (dilution 1:50) or PCNA (dilution 1:100). Negative controls consisted of tissue sections incubated with Tris-buffered saline (TBS) instead of the primary antibody. The immunoreactivity was then visualized by incubating the samples in 3,3'-diaminobenzedine. Finally, the slides were counterstained with hematoxylin. To evaluate the expression of MMP-9, VEGF and PCNA, all slides were examined and scored by two independent pathologists who were blinded to the animal data. A few cases with discrepant scores were reevaluated to reach a final agreement. Any slides that exhibited diffuse immunostaining or $>50 \%$ tumor cells were classified as $(++),>10 \%$ but $<50 \%$ as $(+)$, and $<10 \%$ as $(-)$.

\section{Western blotting}

Proteins for Western blotting were isolated from fresh-frozen tissue using T-Per extraction reagent (Pierce Biotechnology, Rockford, IL, USA) according to the manufacturer's recommendations. The supernatants were frozen at $-80^{\circ} \mathrm{C}$ until use. The proteins were fractionated by $10 \%$ SDS-PAGE and followed by electrotransfer onto nitrocellulose filters (Bio-Rad, CA, USA). The filters were blocked at $4{ }^{\circ} \mathrm{C}$ overnight with a blocking buffer $(\mathrm{pH} 7.6)$ that contained $5 \%$ non-fat dry milk. The filters were incubated with a primary monoclonal antibody to MMP-9 (1:200; Abcam), VEGF (1:200; Abcam), PCNA (1:200; Abcam), and a secondary antimouse HRP-antibody (1:2000; Santa Cruz Biotechnology, Santa Cruz, CA, USA) for $2 \mathrm{~h}$ at room temperature. Immunoreactive bands were visualized using ECL detection reagents (Amersham Pharmacia Biotech, Little Chalfont, Bucks, UK). 


\section{ELISA}

Expression of hepatocyte growth factor (HGF) in tissues was measured using the ELISA Kit for Rabbit HGF according to the manufacturer's instructions (USCN Life Science, Wuhan, China). Expression of interleukin 6 (IL-6) in tissues was measured using the ELISA Kit for Rabbit IL-6 according to the manufacturer's instructions (USCN Life Science, Wuhan, China).

\section{Tumor reinoculation}

The rabbits were sacrificed and the liver tumors were harvested simultaneously 10 days after RFA. The harvested tumors were placed in saline solution and cut into cubes of $1 \mathrm{~mm}^{3}$. Only portions of tumor tissue that did not show any macroscopic signs of necrosis were used. The tumor tissue was reinoculated subcutaneously into the hind legs of the rabbits as depicted in Fig. 1. Tumor sizes were measured every 1-2 days, with tumor volumes calculated according to the formula [14]: $\mathrm{V}=\mathrm{ab}^{2} / 2$, where, $\mathrm{a}$ is the longest and $b$ the smallest diameter of the tumor in vivo. Rabbits were sacrificed 21 days after reinoculation or when they became moribund. The tumor, liver and lungs were carefully dissected and examined.

\section{Statistical analysis}

Data were presented as the means \pm SD for the indicated number of separate experiments. Statistical analysis was performed using SPSS version 11.5. One-way ANOVA followed by the Newman-Keuls test, Kruskal-Wallis H test, Mann-Whitney test and Student's $t$ test were used to evaluate statistical significance and $P<0.05$ was considered significant.

\section{Results}

Effects of low temperature of RFA at the target sites on growth of hepatic VX2 carcinoma

We showed in our previous experiments that residual hepatic VX2 carcinoma could be seen microscopically in groups I, II and III. We determined the effects of $5 \mathrm{~min}$ RFA at each temperature on the growth of hepatic VX2 carcinoma. The changes in tumor volume were $24.21 \pm$ $3.94 \mathrm{~cm}^{3}$ in group I, $17.28 \pm 1.84 \mathrm{~cm}^{3}$ in group II and $15.48 \pm 0.91 \mathrm{~cm}^{3}$ in group III, which were all larger than that in the control group $\left(12.63 \pm 1.87 \mathrm{~cm}^{3}\right)$. It seemed that the lower the temperature of RFA was, the larger the tumor volume was (Fig. 3).

\section{Effects of low temperature of RFA at the target sites on lung metastasis of hepatic VX2 carcinoma}

We examined by gross observation lung metastasis of hepatic VX2 carcinoma after RFA at low temperature. Quantifiable metastatic nodules were taken to be those structures of a white-grey coloration that could be distinguished on the lung surface and which was

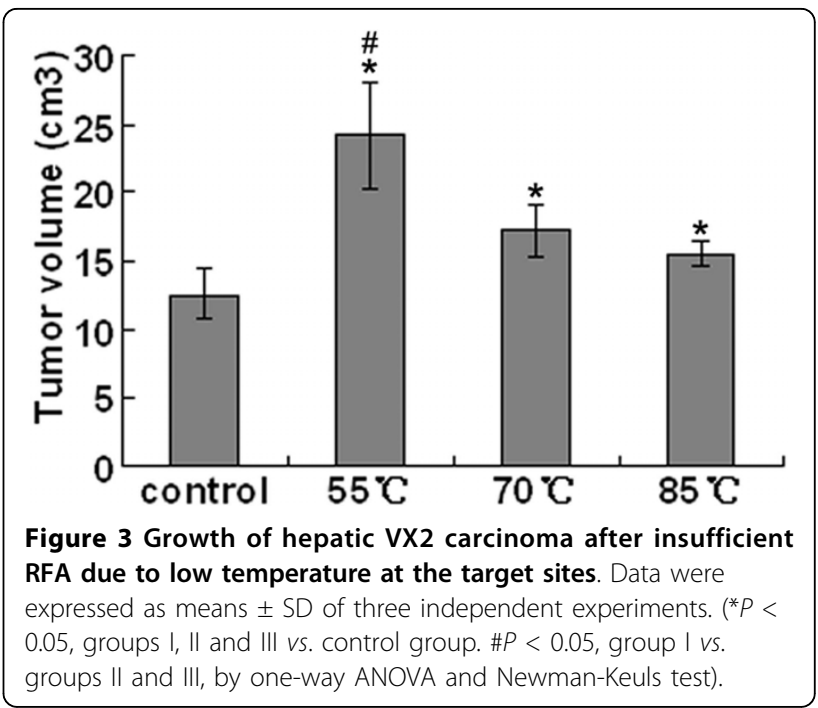

sufficiently separated from each other to be counted individually (Fig. 4A and 4B). The numbers of metastatic nodules are shown in Fig. 5. The control group had between 55 and 80 metastatic nodules randomly distributed over the lung surface, with a mean of $69.0 \pm 10.5$. Group I showed a mean of $302.2 \pm 21.6$, group II, a mean of $137.2 \pm 16.3$, and group III, a mean of $99.6 \pm$ 10.5. Group I was treated with the lowest temperature, therefore, it showed the greatest increase in metastatic nodules compared with all the other groups $(P<0.05)$.

\section{Immunohistochemical assay}

MMP-9, VEGF and PCNA were found to be mainly expressed in cancerous lesions, but also in some normal tissues (Fig. 6). In vitro cell invasiveness was assessed using anti-MMP-9 antibody. In vitro cell proliferation and angiogenesis were evaluated using anti-PCNA and anti-VEGF antibodies, respectively (Fig. 6). The percentage of positive MMP-9, VEGF and PCNA tumor cells in the RFA treatment groups were markedly higher than that in the control group (Table $1, P<0.05$ ). Compared with groups II and III, the percentage of positive MMP9, VEGF and PCNA tumor cells in group I was even higher $(P<0.05)$.

\section{MMP-9, VEGF and PCNA expression in residual hepatic VX2 carcinoma tissues}

Expression of MMP-9 in tumor tissues was markedly decreased in the control group, and incomplete RFA due to low temperature at the target sites significantly increased MMP-9 level in the other groups (Fig. 7). Similarly, incomplete RFA significantly elevated protein expression of VEGF and PCNA in groups I, II and III. At the same time, expression of VEGF and PCNA was markedly decreased in tumor tissues in the control 


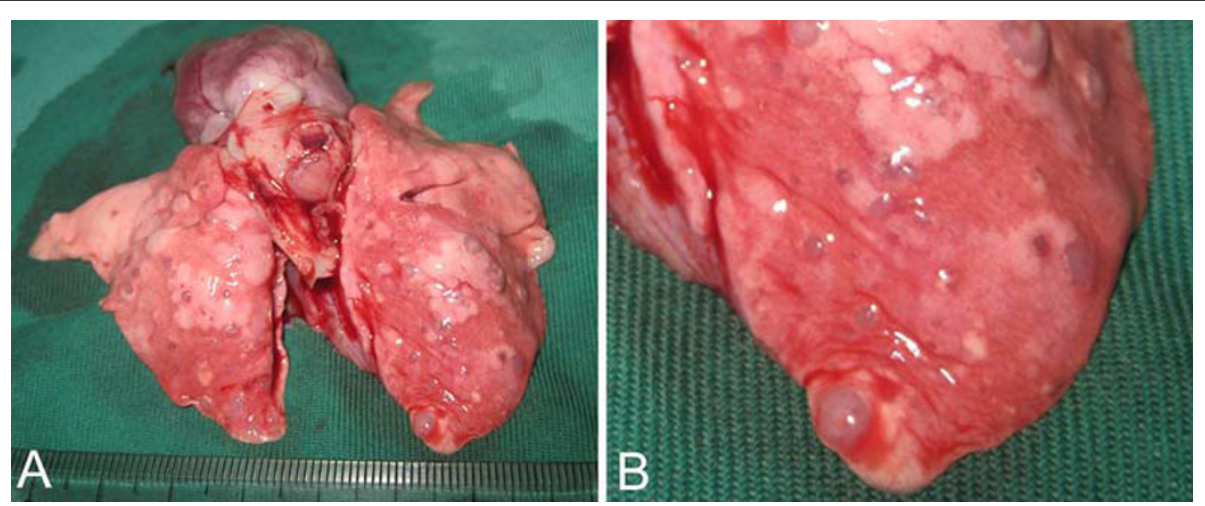

Figure 4 Macroscopic characteristics of pulmonary metastatic nodules. A. Macroscopic view of the lung. B. Fractionated view of the lung, which has been magnified to show the details of the metastatic nodules.

group (Fig. 7). The lower the target temperature of RFA was, the higher was the expression of MMP-9, VEGF and PCNA in residual hepatic VX2 carcinoma tissues. These results had a similar trend as those of the immunohistochemical assays.

Tissue levels of HGF and IL- 6 at the time of animal killing To assess whether any cytokines from the tumor microenvironment might be involved in rapid tumor progression after incomplete RFA, the levels of HGF and IL-6 were determined in tumor and normal tissues from the same liver at the time of animal killing. Expression of HGF and IL-6 in the tumor tissues of group I increased dramatically in comparison with that in the control group. At the same time, the concentrations of HGF and IL- 6 in non-ablated liver tissues in group I were

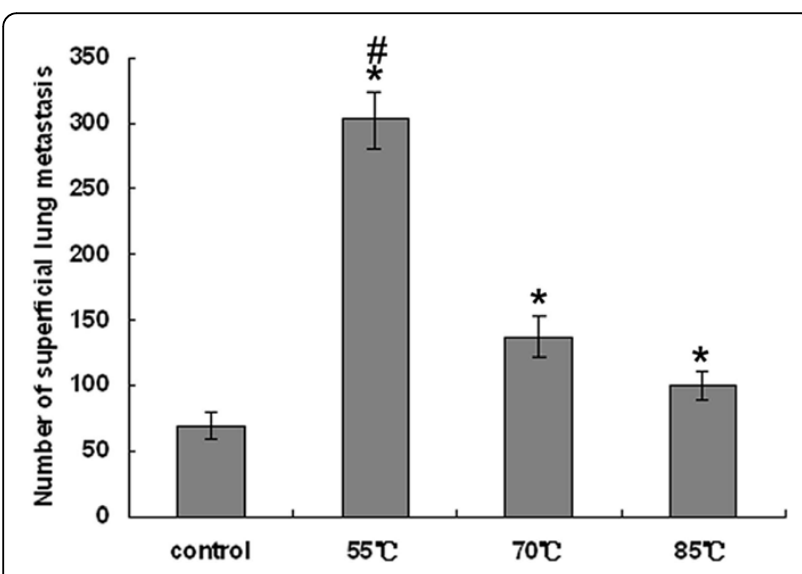

Figure 5 Frequency of pulmonary metastatic nodules in the control group and groups treated with RFA at different low target temperatures. Data were expressed as means \pm SD of three independent experiments. ${ }^{*} P<0.05$, groups I, II and III vs. control group. $\# P<0.05$, group I vs. groups II and III by one-way ANOVA and Newman-Keuls test). much higher than those in liver tissues in the control group (Fig. 8).

\section{Measurement of tumor growth and metastasis after reinoculation}

To demonstrate further the role of low temperature of RFA at the target sites in the rapid progression of residual hepatic VX2 carcinoma, tumor tissues that survived the first RFA at $55^{\circ} \mathrm{C}$ were reinoculated to other normal rabbits. The tumor growth and metastasis were carefully observed individually. It was found that tumor growth and lung metastasis in the RFA groups were much more obvious than in the control group (Figs. 9 and 10). However, no liver metastasis was detected in any of the groups.

\section{Discussion}

It was demonstrated directly or indirectly in our study that residual tumor was prone to proliferation, invasion and metastasis when the local ablative temperature was not sufficiently high. Besides, it seemed that the lower the target temperature was, the more significant were the local proliferation and distant metastasis (e.g. to the lungs) of the tumor. It is known that different cells, such as tumor cells, have different endurance to heat. Some cells can even survive high temperature from 50$55^{\circ} \mathrm{C}$. However, cells can seldom survive temperatures above $55^{\circ} \mathrm{C}$ [9]. Therefore, it seems that most residual tumor and rapid progression should occur when the temperature is below $55^{\circ} \mathrm{C}$, which is consistent with the results of our study.

In clinical settings, although the target temperature can be set as high as $105-115^{\circ} \mathrm{C}$ during RFA, only the tissues that surround the electrodes can reach that temperature [15]. In fact, the real temperature of the tumor tissue between the two adjacent electrodes is lower than the target temperature because of the "heat sink" effect of blood flow [5]. Residual tumor can occur whenever 


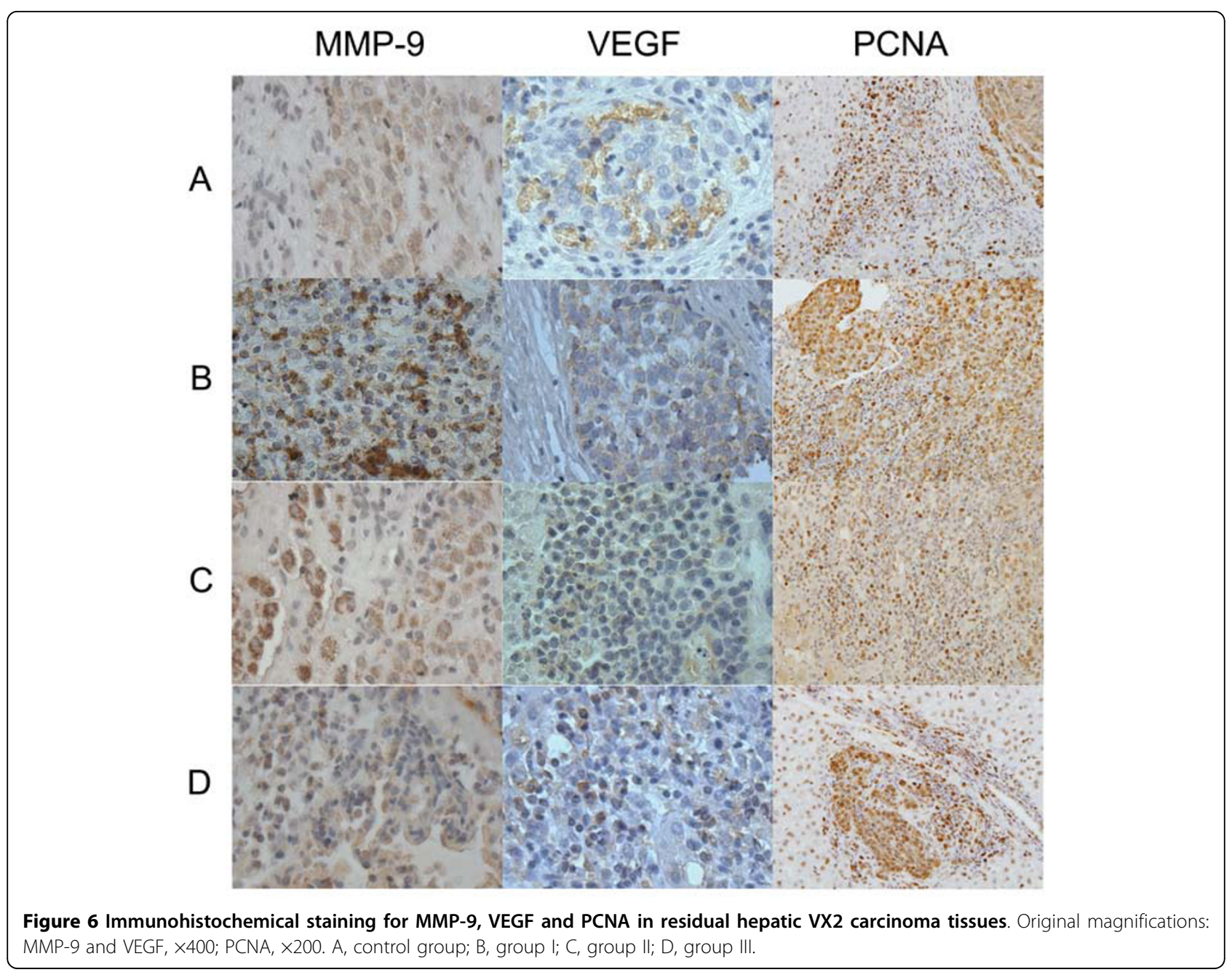

the local ablative temperature is sufficiently low. In the present study, the VX2 nodules were transplanted into the liver rather than derived from the liver itself, therefore, the feeding artery and the heat sink effect were less than those for HCC. The real ablative temperature of the tumor might be nearer to the target temperature, compared with the clinical situation. This was why we chose $85^{\circ} \mathrm{C}$ as the highest RFA temperature.

At present, a large number of molecular factors have been shown to be associated with HCC invasion and metastasis, such as PCNA, MMP-9, VEGF, HGF and IL6. PCNA is a nuclear protein that plays a key role in cell proliferation, DNA repair and cell cycle control [16]. In cirrhotic patients, a high level of PCNA immunolabeling is associated with an increased risk of HCC $[17,18]$, and in HCC, high PCNA values are associated with poor prognosis [17]. Cell invasion is a major component of the complex multistep process of tumor metastasis. Invasion of malignant tumor cells requires destruction of basement membranes and proteolysis of extracellular matrix (ECM). Of the several families of ECM-degrading enzymes, the most extensive are the MMPs, which are a large family of structurally related zinc endopeptidases that collectively degrade most of the ECM components $[19,20]$. Among previously reported human MMPs, MMP-9 is thought to be a vital enzyme for degrading type IV collagen and is postulated to play an important role in HCC invasion and metastasis $[21,22]$.

Tumor angiogenesis is another crucial step in the growth and metastasis of cancer, including HCC, and has drawn much attention in recent years $[23,24]$. Hence, the molecular basis of tumor angiogenesis has been a major interest in the field of cancer research. The VEGF pathway is well established as an important driving force of this process [25]. To date, increasing evidence indicates that tumor-stromal cell interactions have a crucial role in tumor initiation and progression [26]. These interactions modify cellular compartments, which leads to the co-evolution of tumor cells and their 
Table 1 Immunohistochemical results of MMP-9, VEGF and PCNA

\begin{tabular}{|c|c|c|c|c|c|c|}
\hline & Group & $\mathrm{N}$ & $\begin{array}{r}\text { Expression } \\
\text { density }\end{array}$ & No of cases & $\%$ & $P$ \\
\hline \multirow[t]{16}{*}{ MMP-9 } & I & 15 & & & & \\
\hline & & & ++ & 13 & 86.67 & $<0.01$ \\
\hline & & & + & 2 & 13.33 & \\
\hline & & & - & 0 & 0.00 & \\
\hline & $\|$ & 15 & & & & \\
\hline & & & ++ & 5 & 33.33 & \\
\hline & & & + & 9 & 60.00 & \\
\hline & & & - & 1 & 6.67 & \\
\hline & III & 15 & & & & \\
\hline & & & ++ & 4 & 26.67 & \\
\hline & & & + & 10 & 66.67 & \\
\hline & & & - & 1 & 6.67 & \\
\hline & Control & 15 & & & & \\
\hline & & & ++ & 0 & 0.00 & \\
\hline & & & + & 7 & 46.67 & \\
\hline & & & - & 8 & 53.33 & \\
\hline \multirow[t]{16}{*}{ VEGF } & I & 15 & & & & \\
\hline & & & ++ & 12 & 80.00 & $<0.01$ \\
\hline & & & + & 3 & 20.00 & \\
\hline & & & - & 0 & 0.00 & \\
\hline & $\|$ & 15 & & & & \\
\hline & & & ++ & 5 & 33.33 & \\
\hline & & & + & 9 & 60.00 & \\
\hline & & & - & 1 & 6.67 & \\
\hline & III & 15 & & & & \\
\hline & & & ++ & 3 & 20.00 & \\
\hline & & & + & 10 & 66.67 & \\
\hline & & & - & 2 & 13.33 & \\
\hline & Control & 15 & & & & \\
\hline & & & ++ & 0 & 0.00 & \\
\hline & & & + & 6 & 40.00 & \\
\hline & & & - & 9 & 60.00 & \\
\hline \multirow[t]{16}{*}{ PCNA } & I & 15 & & & & \\
\hline & & & ++ & 11 & 73.33 & $<0.01$ \\
\hline & & & + & 4 & 26.67 & \\
\hline & & & - & 0 & 0.00 & \\
\hline & $\|$ & 15 & & & & \\
\hline & & & ++ & 4 & 26.67 & \\
\hline & & & + & 10 & 66.67 & \\
\hline & & & - & 1 & 6.67 & \\
\hline & III & 15 & & & & \\
\hline & & & ++ & 2 & 13.33 & \\
\hline & & & + & 12 & 80.00 & \\
\hline & & & - & 1 & 6.67 & \\
\hline & Control & 15 & & & & \\
\hline & & & ++ & 0 & 0.00 & \\
\hline & & & + & 5 & 33.33 & \\
\hline & & & - & 10 & 66.67 & \\
\hline
\end{tabular}

MMP-9: matrix metalloproteinase 9; VEGF: vascular endothelial growth factor; PCNA: proliferating cell nuclear antigen. Any slides that exhibited diffuse

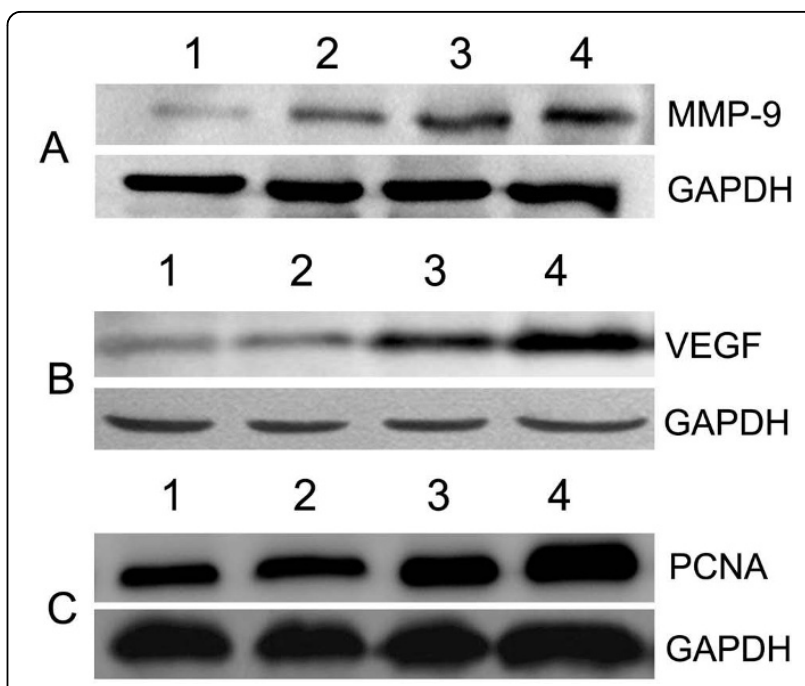

Figure 7 MMP-9, VEGF and PCNA expression in residual hepatic VX2 carcinoma tissues. A, MMP-9; B, VEGF; C, PCNA. 1, control group; 2, group III; 3, group II; 4, group I.

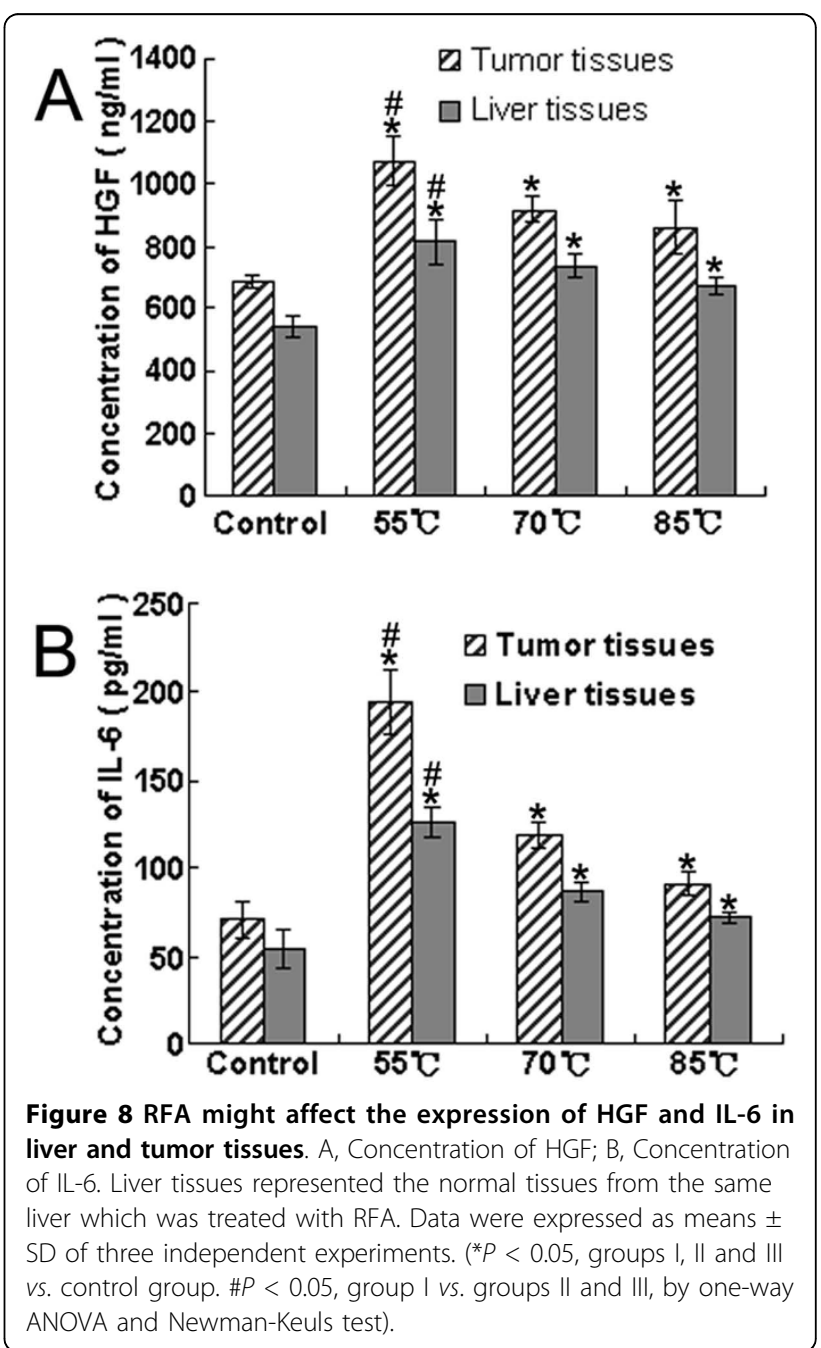




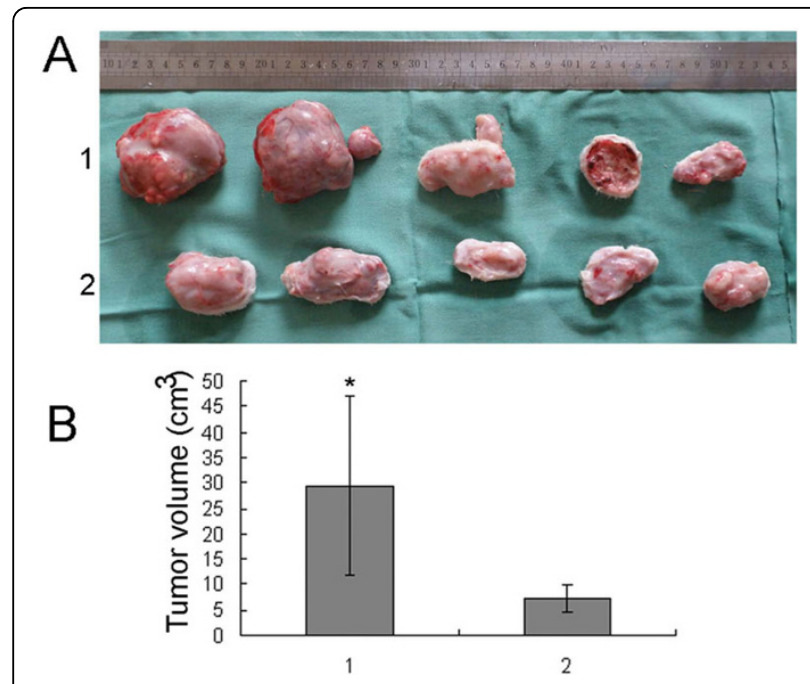

Figure 9 Volumes of hepatic VX2 carcinoma 21 days after reinoculation. A, Photographs of the hepatic VX2 carcinoma of five rabbits selected from the control group and five from group I. 1, Group I, RFA at $55^{\circ} \mathrm{C} ; 2$, control group. The top row shows hepatic VX2 carcinoma of rabbits treated with RFA, and large tumors were seen. The bottom row shows hepatic VX2 carcinoma of control rabbits with smaller tumors. $\mathrm{B}, 1$, group I, RFA at $55^{\circ} \mathrm{C} ; 2$, control

A

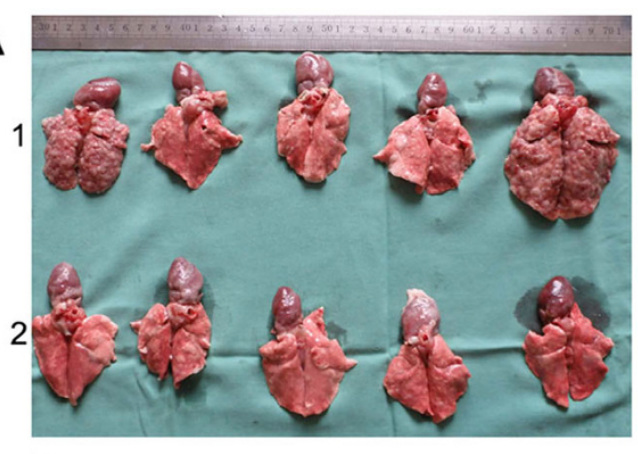

B

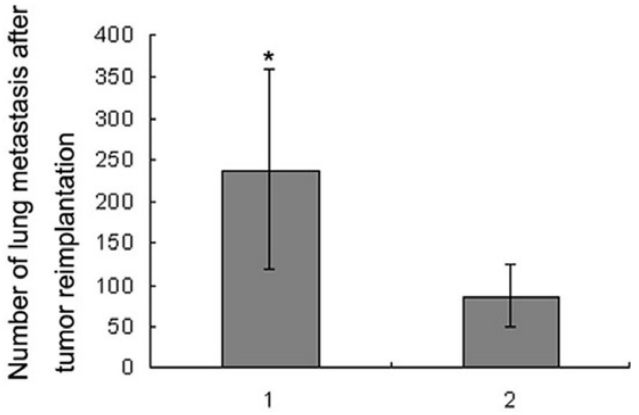

Figure 10 Lung metastasis of hepatic VX2 carcinoma 21 days after reinoculation. $A$, Photographs of the lungs of five rabbits selected from the control group and five from group I. 1, group I, RFA at $55^{\circ} \mathrm{C} ; 2$, control group. The top row shows lungs of rabbits treated with RFA, and numerous, large, white-grey tumors were seen. The bottom row shows lungs of control rabbits with fewer and smaller tumors. $\mathrm{B}, 1$, group I, RFA at $55^{\circ} \mathrm{C} ; 2$, control group. Data are expressed as means \pm SD of three independent experiments. ( ${ }^{*} P<0.05$, by Student's $t$ test) microenvironment. HGF, also known as scatter factor, is produced by non-parenchymal liver cells, and is a multifunctional cytokine of the tumor microenvironment of HCC [27]. HGF accomplishes most of the functions of the invasive program in carcinomas (loss of adhesive junctions, motility, angiogenesis, and survival/apoptosis). HGF receptor, also known as c-Met, plays important roles in angiogenesis and tumor growth [28]. It has been reported that c-Met expression is significantly higher in the invasive type of HCC, as determined by gross type, vessel invasion, intrahepatic metastasis and histological type, and induction of c-Met might be used as a indicator of HCC progression, especially intrahepatic metastasis [29].

IL-6 is a multifunctional regulator of the immune response and hematopoiesis. Recently, it has been reported that expression of IL-6 is correlated with prognosis in various cancer patients [30-32]. Kanazawa et al. [32] have reported that IL-6 can directly influence cell proliferation and the invasion potential as the first step of tumor metastasis. Hong et al. [33] believe that therapeutic targeting of IL- 6 and its receptor in cancer has a strong biological rationale, and there is preliminary evidence to suggest that targeting of the IL- 6 system might be beneficial in the treatment of cancer. In the present study, it was shown that expression of PCNA, MMP-9, VEGF, HGF and IL- 6 in tumor tissues in groups I, II and III, which received incomplete RFA, increased remarkably. Furthermore, it seemed that the lower the target temperature of RFA was, the higher was the expression of these molecular factors. This was consistent with the results of tumor inoculation and reinoculation studies. These data suggest that the residual tumor cells facilitate tumor growth and metastasis through induction of overexpression of PCNA, MMP-9, VEGF, HGF and IL-6.

It is important to clarify the underlying mechanisms of rapid progression of residual HCC after RFA, to optimize the therapeutic principles and strategies of RFA. It has been reported that HGF/c-Met signaling can activate multiple signal transduction pathways, including the Src/focal adhesion kinase pathway, the p120/signal transducer and activator of transcription 3 pathway, the phosphoinositide-3 kinase (PI3K)/Akt pathway, and the MEK/ERK pathway [34,35]. It has been confirmed that the PI3K/Akt and MEK/ERK pathways play a vital role in tumor invasion and metastasis [36-40]. Increasing evidence has demonstrated that the HGF/c-Met signaling pathway could be another valuable pathway for research on tumor target therapy, besides the VEGF signal pathway. HGF/c-Met signaling is activated in angiogenesis and tumor growth, therefore, several strategies have been explored for inhibiting this pathway. Some inhibitors of the HGF/c-Met signaling pathway have been 
developed and introduced into preclinical and phase I and II clinical trials [41]. In our study, we found that expression of HGF in tumor tissues after incomplete RFA was much higher than that in tumor tissues without RFA. This indicates that the HGF/c-Met signaling pathway might be involved in the rapid progression of residual tumor after RFA. Further research in this area could have potential for enhancing the therapeutic effect of RFA on HCC. Another significant finding was that expression of HGF and IL-6 in non-ablated liver tissues in group I were much higher than those in liver tissues in the control group. We supposed that both the liver injury triggered by RFA and autocrine loop in tumor cells may involve in it. However, this needs to be confirmed.

\section{Conclusions}

In conclusion, the results of this study highlight two issues. Firstly, insufficient RFA, which is caused by low temperature at the target sites, could be an important reason for rapid progression of residual hepatic VX2 carcinoma. Secondly, residual hepatic VX2 carcinoma might facilitate rapid tumor progression through induction of overexpression of multiple molecular factors, such as PCNA, MMP-9, VEGF, HGF and IL-6.

\section{Acknowledgements}

The authors appreciate technical assistance from P. Gu and Y. Xie, valuable discussion with Y.Q. Liu, and help from experimental animal facility technicians for animal care. This work was supported by grants from National Natural Science Foundation of China (No.30872490) and Dr. Wu Jieping Medical foundation (No.320675007131).

\section{Authors' contributions}

SK, XD and JK performed the rabbit experiments and ELISA analysis. JG, SW and $Y C$ carried out the immunohistochemistry, XD and JK performed the western blotting. SK, XD and WS conceived and designed the experiments and analyzed the data. The manuscript was written by SK and WS. All authors read and approved the final manuscript.

\section{Competing interests}

The authors declare that they have no competing interests.

Received: 10 March 2010 Accepted: 29 July 2010

Published: 29 July 2010

\section{References}

1. Shariff MI, Cox IJ, Gomaa Al, Khan SA, Gedroyc W, Taylor-Robinson SD: Hepatocellular carcinoma: current trends in worldwide epidemiology, risk factors, diagnosis and therapeutics. Expert Rev Gastroenterol Hepatol 2009, 3(4):353-367.

2. Sun WB: How is radiofrequency ablation going in treating hepatocellular carcinoma in China? Austral-Asian Journal of Cancer 2008, 7(4):221-224.

3. Lau WY, Lai EC: The current role of radiofrequency ablation in the management of hepatocellular carcinoma: a systematic review. Ann Surg 2009, 249(1):20-25.

4. Rhim H, Kim YS, Choi D, Lim HK, Park K: Percutaneous radiofrequency ablation of hepatocellular carcinoma: analysis of 80 patients treated with two consecutive sessions. Eur Radiol 2008, 18(7):1442-1448.

5. Thanos L, Mylona S, Galani P, Pomoni M, Pomoni A, Koskinas I: Overcoming the heat-sink phenomenon: successful radiofrequency thermal ablation of liver tumors in contact with blood vessels. Diagn Interv Radiol 2008, 14(1):51-56.
6. Zhou XP, Yang GS, Cong WM, Lu JH, Zhang SH, Zong M: Retrospective and prospective study on micrometastasis in liver parenchyma surrounding PLC. Chinese Journal of Hepatobiliary Surgery 2005, 11(8):510-514.

7. Seki T, Tamai T, Ikeda K, Imamura M, Nishimura A, Yamashiki N, Nakagawa T, Inoue K: Rapid progression of hepatocellular carcinoma after transcatheter arterial chemoembolization and percutaneous radiofrequency ablation in the primary tumour region. Eur J Gastroenterol Hepatol 2001, 13(3):291-294.

8. Ruzzenente A, Manzoni GD, Molfetta M, Pachera S, Genco B, Donataccio M, Guglielmi A: Rapid progression of hepatocellular carcinoma after Radiofrequency Ablation. World J Gastroenterol 2004, 10(8):1137-1140.

9. Obara K, Matsumoto N, Okamoto M, Kobayashi M, Ikeda H, Takahashi H, Katakura Y, Matsunaga K, Ishii T, Okuse C, Suzuki M, Itoh F: Insufficient radiofrequency ablation therapy may induce further malignant transformation of hepatocellular carcinoma. Hepatol Int 2008, 2(1):116-123.

10. Kasugai H, Osaki Y, Oka H, Kudo M, Seki T: Severe complications of radiofrequency ablation therapy for hepatocellular carcinoma: an analysis of 3,891 ablations in 2,614 patients. Oncology 2007, 72(Suppl 1):72-75.

11. Kim TJ, Moon WK, Cha JH, Goo JM, Lee KH, Kim KH, Lee JW, Han JG, Weinmann HJ, Chang KH: VX2 carcinoma in rabbits after radiofrequency ablation: comparison of MR contrast agents for help in differentiating benign periablational enhancement from residual tumor. Radiology 2005, 234(2):423-430.

12. Gu T, Li CX, Feng Y, Wang Q, Li CH, Li CF: Trans-arterial gene therapy for hepatocellular carcinoma in a rabbit model. World J Gastroenterol 2007, 13(14):2113-2117.

13. Martinez C, Vicente V, Yanez MJ, Garcia JM, Canteras M, Alcaraz M: Experimental model of pulmonary metastasis treatment with IFNalpha. Cancer Lett 2005, 225(1):75-83.

14. Carlsson G, Gullberg B, Hafstrom L: Estimation of liver tumor volume using different formulas - an experimental study in rats. J Cancer Res Clin Oncol 1983, 105(1):20-23.

15. Rossi S, Garbagnati F, Lencioni R, Allgaier HP, Marchiano A, Fornari F, Quaretti P, Tolla GD, Ambrosi C, Mazzaferro V, Blum HE, Bartolozzi C: Percutaneous radio-frequency thermal ablation of nonresectable hepatocellular carcinoma after occlusion of tumor blood supply. Radiology 2000, 217(1):119-126.

16. Stoimenov I, Helleday T: PCNA on the crossroad of cancer. Biochem Soc Trans 2009, 37(Pt 3):605-613.

17. Stroescu C, Dragnea A, Ivanov B, Pechianu C, Herlea V, Sgarbura O, Popescu A, Popescu I: Expression of p53, Bcl-2, VEGF, Ki67 and PCNA and prognostic significance in hepatocellular carcinoma. J Gastrointestin Liver Dis 2008, 17(4):411-417.

18. Ballardini G, Groff P, Zoli M, Bianchi G, Giostra F, Francesconi R, Lenzi M, Zauli D, Cassani F, Bianchi F: Increased risk of hepatocellular carcinoma development in patients with cirrhosis and with high hepatocellular proliferation. J Hepatol 1994, 20(2):218-222.

19. Roy R, Yang J, Moses MA: Matrix metalloproteinases as novel biomarkers and potential therapeutic targets in human cancer. J Clin Oncol 2009, 27(31):5287-5297.

20. Li X, Wu JF: Recent developments in patent anti-cancer agents targeting the matrix metalloproteinases (MMPs). Recent Pat Anticancer Drug Discov 5(2):109-141.

21. Yang $P$, Yuan $W$, He J, Wang J, Yu L, Jin $X$, Hu $Y$, Liao $M$, Chen Z, Zhang $Y$ : Overexpression of EphA2, MMP-9, and MVD-CD34 in hepatocellular carcinoma: Implications for tumor progression and prognosis. Hepatol Res 2009, 39(12):1169-1177.

22. Chen JS, Wang Q, Fu XH, Huang XH, Chen XL, Cao LQ, Chen LZ, Tan HX, Li W, Bi J, Zhang LJ: Involvement of PI3K/PTEN/AKT/mTOR pathway in invasion and metastasis in hepatocellular carcinoma: Association with MMP-9. Hepatol Res 2009, 39(2):177-186.

23. Raskopf E, Vogt A, Sauerbruch T, Schmitz V: siRNA targeting VEGF inhibits hepatocellular carcinoma growth and tumor angiogenesis in vivo. J Hepatol 2008, 49(6):977-984.

24. Sugimachi K, Tanaka S, Terashi T, Taguchi K, Rikimaru T, Sugimachi K: The mechanisms of angiogenesis in hepatocellular carcinoma: angiogenic switch during tumor progression. Surgery 2002, 131(1 Suppl):S135-141. 
25. Hicklin DJ, Ellis LM: Role of the vascular endothelial growth factor pathway in tumor growth and angiogenesis. J Clin Oncol 2005, 23(5):1011-1027.

26. Polyak K, Haviv I, Campbell IG: Co-evolution of tumor cells and their microenvironment. Trends Genet 2009, 25(1):30-38.

27. Desiderio MA: Hepatocyte growth factor in invasive growth of carcinomas. Cell Mol Life Sci 2007, 64(11):1341-1354.

28. You WK, McDonald DM: The hepatocyte growth factor/c-Met signaling pathway as a therapeutic target to inhibit angiogenesis. BMB Rep 2008, 41(12):833-839.

29. Osada S, Kanematsu M, Imai H, Goshima S: Clinical significance of serum HGF and c-Met expression in tumor tissue for evaluation of properties and treatment of hepatocellular carcinoma. Hepatogastroenterology 2008, 55(82-83):544-549.

30. Hodge DR, Hurt EM, Farrar WL: The role of IL-6 and STAT3 in inflammation and cancer. Eur J Cancer 2005, 41(16):2502-2512.

31. Paule B, Terry S, Kheuang $L$, Soyeux $P$, Vacherot F, de la Taille A: The NFkappaB/L-6 pathway in metastatic androgen-independent prostate cancer: new therapeutic approaches? World J Urol 2007, 25(5):477-489.

32. Kanazawa $T$, Nishino $H$, Hasegawa $M$, Ohta $Y$, lino $Y$, Ichimura $K$, Noda $Y$ : Interleukin-6 directly influences proliferation and invasion potential of head and neck cancer cells. Eur Arch Otorhinolaryngol 2007, 264(7):815-821.

33. Hong DS, Angelo LS, Kurzrock R: Interleukin-6 and its receptor in cancer: implications for Translational Therapeutics. Cancer 2007, 110(9):1911-1928.

34. Ponzetto C, Bardelli A, Zhen Z, Maina F, dalla Zonca P, Giordano S, Graziani A, Panayotou G, Comoglio PM: A multifunctional docking site mediates signaling and transformation by the hepatocyte growth factor/ scatter factor receptor family. Cell 1994, 77(2):261-271.

35. Ponzetto C, Bardelli A, Maina F, Longati P, Panayotou G, Dhand R, Waterfield MD, Comoglio PM: A novel recognition motif for phosphatidylinositol 3-kinase binding mediates its association with the hepatocyte growth factor/scatter factor receptor. Mol Cell Biol 1993, 13(8):4600-4608.

36. Lee WJ, Chen WK, Wang CJ, Lin WL, Tseng TH: Apigenin inhibits HGFpromoted invasive growth and metastasis involving blocking PI3K/Akt pathway and beta 4 integrin function in MDA-MB-231 breast cancer cells. Toxicol Appl Pharmacol 2008, 226(2):178-191.

37. Lee KH, Choi EY, Kim MK, Hyun MS, Jang Bl, Kim TN, Kim SW, Song SK, Kim JH, Kim JR: Regulation of hepatocyte growth factor-mediated urokinase plasminogen activator secretion by MEK/ERK activation in human stomach cancer cell lines. Exp Mol Med 2006, 38(1):27-35.

38. Lee KH, Kim JR: Hepatocyte growth factor induced up-regulations of VEGF through Egr-1 in hepatocellular carcinoma cells. Clin Exp Metastasis 2009, 26(7):685-692.

39. Zeng Q, Chen S, You Z, Yang F, Carey TE, Saims D, Wang CY: Hepatocyte growth factor inhibits anoikis in head and neck squamous cell carcinoma cells by activation of ERK and Akt signaling independent of NFkappa B. J Biol Chem 2002, 277(28):25203-25208.

40. Ma PC, Tretiakova MS, Nallasura V, Jagadeeswaran R, Husain AN, Salgia R: Downstream signalling and specific inhibition of C-MET/HGF pathway in small cell lung cancer: implications for tumour invasion. Br I Cancer 2007, 97(3):368-377.

41. Toschi L, Janne PA: Single-agent and combination therapeutic strategies to inhibit hepatocyte growth factor/MET signaling in cancer. Clin Cancer Res 2008, 14(19):5941-5946.

doi:10.1186/1479-5876-8-73

Cite this article as: Ke et al: Low temperature of radiofrequency ablation at the target sites can facilitate rapid progression of residual hepatic VX2 carcinoma. Journal of Translational Medicine 2010 8:73.

\section{Submit your next manuscript to BioMed Central and take full advantage of:}

- Convenient online submission

- Thorough peer review

- No space constraints or color figure charges

- Immediate publication on acceptance

- Inclusion in PubMed, CAS, Scopus and Google Scholar

- Research which is freely available for redistribution

Submit your manuscript at www.biomedcentral.com/submit
Ciomed Central 